\title{
Long-term changes in soil fertility in hill country
}

\author{
A.D. MACKAY and D.A. COSTALL' \\ AgResearch Grasslands, Private Bag 11008, Palmerston North, New Zealand \\ alec.mackay@agresearch.co.nz
}

\begin{abstract}
It has been more than 10 years since the last comprehensive soil sampling of the long term phosphorus (P) fertiliser and sheep grazing farmlet study established at the AgResearch Ballantrae Hill Country Research Station in 1975. This paper reports the findings from a sampling in October 2014 of the soils in the farmlets that have had no fertiliser since 1980 (LFNF), received $125 \mathrm{~kg} / \mathrm{ha} /$ year of superphosphate since 1980 (LFLF) or $375 \mathrm{~kg} / \mathrm{ha} /$ year of superphosphate since 1980 (HFHF). Increases in total $\mathrm{P}$ levels in the soil reflect the differences in $\mathrm{P}$ inputs between the LFNF, LFLF and HFHF farmlets over the last 40 years. In sharp contrast total sulphur (S) levels in soils have showed little change, despite the large amounts of sulphur applied in superphosphate each year. Exchangeable calcium $(\mathrm{Ca})$ levels have increased on the farmlets receiving fertiliser, reflecting the $\mathrm{Ca}$ inputs in superphosphate, while magnesium $(\mathrm{Mg})$ levels are lower in the HFHF farmlet. Potassium has shown little change, with the exception of increases on low slope areas in the HFHF farmlet. Olsen P levels have not changed in the topsoil $(0-75 \mathrm{~mm})$ in the HFHF since the 2003 sampling, despite annual $\mathrm{P}$ inputs in excess of maintenance. The absence of any change might be explained by the finding that $\mathrm{P}$ is accumulating in large amounts in the $75-150 \mathrm{~mm}$ soil depths on low slopes in the HFHF farmlet. This finding was unexpected serving to highlight the insights these long-term experimental studies provide to both science and industry.
\end{abstract}

Keywords: Long term fertiliser study, P fertiliser, Olsen P, soil fertility

\section{Key message}

- Long-term fertiliser and sheep grazing field studies are an invaluable resource for both science and the industry.

\section{Introduction}

The long term fertiliser and sheep grazing farmlet study established at the AgResearch Ballantrae Hill Country Research Station in 1975 provides invaluable insights into the interactions between phosphorus $(\mathrm{P})$ fertiliser use, soil fertility and biology, and pasture and animal production (Clark et al. 1990; Mackay \& Lambert 2011). Only the 'Irrigation and Fertiliser study' at AgResearch Winchmore Research Station has been in place longer (Smith et al. 2012). Since detailed monitoring at Ballantrae ceased in 1990, the fertiliser treatments have been maintained, along with nominal sheep stocking rates and grazing practices. An update of the changes in sheep stocking rate and soil fertility was reported by Mackay \& Lambert (2011), with the findings at that time also compared with earlier published data from this long-term site (Lambert et al. 1990). Since 1980, 130+ research and conference publications have reported on studies utilising the longterm fertiliser and sheep grazing study at Ballantrae, and a SCOPUS $\AA$ database analysis revealed these have been cited more than 750 times. This field site provides one of the few opportunities to track ongoing changes in the chemistry, biology and physical properties of soils, the fate of contaminants from fertiliser, pasture composition and performance, changes in pest and weeds through to animal production.

This paper reports the findings from a sampling in October 2014 of the soils on the farmlets that have had no fertiliser since 1980 (LFNF), received $125 \mathrm{~kg} /$ ha/year of superphosphate since 1980 (LFLF) and received $375 \mathrm{~kg} / \mathrm{ha} /$ year of superphosphate since 1980 (HFHF). It has been more than 10 years since the last comprehensive soil sampling of the long term fertiliser and sheep grazing farmlet study.

\section{Materials and methods}

Field location

The study was conducted at the AgResearch Ballantrae Hill Country Research Station, Southern Hawke's Bay, New Zealand (408180S, 1758500E). Ballantrae, typical of much of the North Island's steep, pastoral hill country covering 3.5 million ha ( $28 \%$ of the total area of farmland in New Zealand), is located 125 to $350 \mathrm{~m}$ above sea level with an average air temperature of $12.8^{\circ} \mathrm{C}$ and annual rainfall of $1270 \mathrm{~mm}$ distributed evenly throughout the year. Brown and Pallic Soils (Hewitt 1998) are present i.e. yellow-brown earths and intergrades to yellow-grey earths, and related steepland soils, mainly formed from tertiary sandstone, siltstone, and mudstone, but with some loess influence in areas.

\section{Long term fertiliser and sheep grazing study (1975- 2014)}

Self-contained experimental farmlets, two receiving low (LF) and two receiving high (HF) fertiliser inputs were established in 1975 (Lambert et al. 1990). 


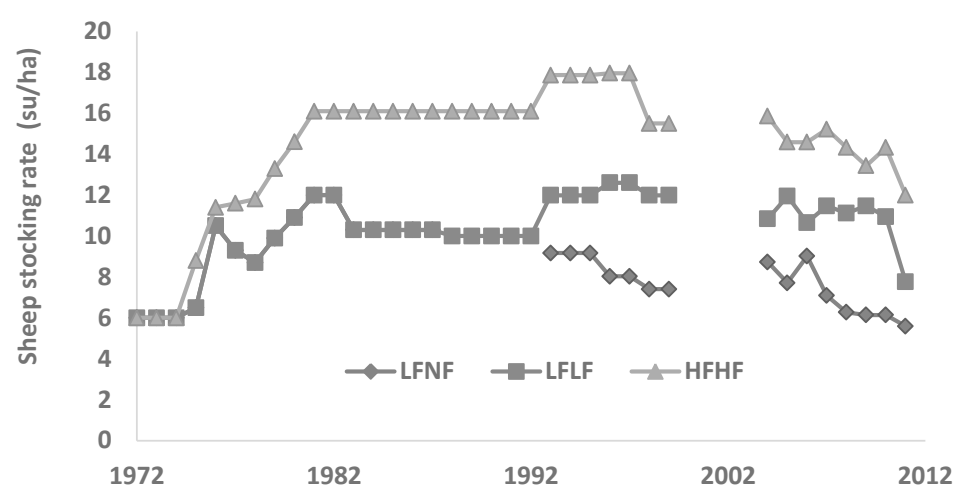

Figure 1 Nominal sheep stocking rates (su/ha) on the farmlets that has had no fertiliser since 1980 (LFNF), received $125 \mathrm{~kg} / \mathrm{ha} /$ year of superphosphate since 1980 (LFLF) or $375 \mathrm{~kg} / \mathrm{ha} / \mathrm{year}$ of superphosphate since 1980 (HFHF) (Mackay \& Lambert 2011).

Since 1980, one of the LF farmlets has received 125 $\mathrm{kg}$ superphosphate/ha/year and has been stocked by sheep at $10.6 \mathrm{su} / \mathrm{ha}$ (LFLF); one of the high fertiliser farmlets has received $375 \mathrm{~kg} \mathrm{SSP} / \mathrm{ha} /$ year and has been stocked at $16.0 \mathrm{su} / \mathrm{ha}$ (HFHF). Since 1980 fertiliser has been withheld from one of the low (LFNF) fertiliser farmlets. Ground limestone was applied on the HFHF pasture in $1975(1250 \mathrm{~kg} / \mathrm{ha})$ and in $1979(2500 \mathrm{~kg} / \mathrm{ha})$. Nitrogen (N), as urea, was applied to HFHF in 1975 at $20 \mathrm{~kg} / \mathrm{ha}$. The farmlets are continuously grazed by breeding ewes, with replacements introduced in the autumn.

\section{Measurements and analysis}

Occasional measurements of soil fertility and pasture production have been made on the farmlets since detailed monitoring ceased in the late 1980s. Since then the objective has been to maintain sheep stocking rates close to 10.6 and $16.0 \mathrm{su} / \mathrm{ha}$ on the LFLF and HFHF farmlets, respectively, with annual superphosphate inputs of 125 and $375 \mathrm{~kg} / \mathrm{ha} /$ year, respectively (Figure 1). Sheep stocking rates have slowly decreased on the LFNF farmlets since the early 1990s (Figure 1). Sheep grazing has been a combination of set-stocking with some rotational grazing within each farmlet in the last 15 years.

In October 2014, soil samples were taken to two depths $(0-75,75-150 \mathrm{~mm})$ from 18 sites from each of the LFNF, LFLF and HFHF farmlets. The 18 sites in each farmlet covered three slope classes (low (0$\left.12^{\circ}\right)$, medium $\left(13-25^{\circ}\right)$ and steep $\left(>25^{\circ}\right)$ ) and three aspects (centred on the North East, North West and South) and two replicates. Bulk density was assessed at the time of sampling at all sites. Soils were analysed for total $\mathrm{P}, \mathrm{S}, \mathrm{C}$ and $\mathrm{N}, \mathrm{pH}$ in water, Olsen $\mathrm{P}$, exchangeable cations and sulphate-sulphur using a commercial laboratory.

\section{Results and Discussion}

Changes in total phosphorus, sulphur, carbon and nitrogen

Differences in total $\mathrm{P}$ in the soil reflect the difference in $\mathrm{P}$ fertiliser inputs over the last 40 years (Table 1). For example, total $\mathrm{P}$ in the $0-75 \mathrm{~mm}$ and $75-150 \mathrm{~mm}$ soil depths averaged across the three slopes and three aspects of the HFHF farmlet averaged 867 and 619 $\mu \mathrm{g} / \mathrm{g}$, respectively, compared to 357 and $311 \mu \mathrm{g} / \mathrm{g}$ in the same two depths in the LFNF farmlet (Table1). In sharp contrast and consistent with the findings of Saggar et al. (1990), there was little accumulation of $\mathrm{S}$ in the soil profile, despite the addition of 14 and $41 \mathrm{~kg} \mathrm{~S} / \mathrm{ha} /$ year in the 125 and $375 \mathrm{~kg}$ superphosphate, respectively, applied each year. Total $\mathrm{S}$ in the 0-75 and $75-150 \mathrm{~mm}$ soil depths averaged across the three slopes and three aspects in the HFHF farmlet averaged 490 and $397 \mu \mathrm{g} / \mathrm{g}$, respectively, compared to 450 and $387 \mu \mathrm{g} / \mathrm{g}$ in the same two depths in the LFNF farmlet (Table 1). Saggar et al. (1990) estimated that close to $70 \%$ of the applied S is lost by leaching in this low anion storage capacity sedimentary soil. The limited accumulation of $\mathrm{S}$ in this soil, which in these hill soils is in the organic fraction, is a function of the amount of organic $\mathrm{N}$ that is also accumulating. There are few differences in total soil $\mathrm{N}$ or $\mathrm{C}$ contents between the farmlets despite large differences in primary production. More detailed discussion of the long-term influence of fertiliser and grazing on soil $\mathrm{C}$ and $\mathrm{N}$ is beyond the scope of this paper.

Changes in bulk density, pH, sulphate-S and exchangeable cations

Bulk density in the topsoil $(0-75 \mathrm{~mm})$ across the three slopes and aspects for each of the LFNF, LFLF and

Table 1 Total phosphorus (P) and sulphur (S) $(\mu \mathrm{g} / \mathrm{g})$ in the 0-75 $\mathrm{mm}$ and $75-150 \mathrm{~mm}$ soil depths averaged across the three slopes and aspects for the farmlets that has had no fertiliser since 1980 (LFNF), received $125 \mathrm{~kg} / \mathrm{ha} /$ year of superphosphate since 1980 (LFLF) or $375 \mathrm{~kg} / \mathrm{ha} /$ year of superphosphate since 1980 (HFHF).

\begin{tabular}{lcccc}
\hline Nutrient & $\begin{array}{c}\text { Soil depth } \\
(\mathbf{m m})\end{array}$ & LFNF & LFLF & HFHF \\
\hline Total P $(\mu \mathrm{g} / \mathrm{g})$ & $0-75$ & 357 & 433 & 867 \\
& $75-150$ & 311 & 335 & 619 \\
\hline Total S $(\mu \mathrm{g} / \mathrm{g})$ & $0-75$ & 450 & 466 & 490 \\
& $75-150$ & 387 & 377 & 397 \\
\hline
\end{tabular}


HFHF farmlets averaged $0.75,0.74$ and $0.72 \mathrm{Mg} / \mathrm{m}^{3}$, respectively, with the trend for higher bulk density on the low slope areas of HFHF compared to the other two farmlets. Soil $\mathrm{pH}$ levels in the topsoil $(0-75 \mathrm{~mm})$ across the three slopes and aspects for each of the LFNF, LFLF and HFHF farmlets averaged 5.5, 5.4 and 5.2, respectively. These are higher than the soil $\mathrm{pH}$ values reported by Lambert et al. (2000) of 5.0 and 5.15, for the LFLF and HFHF farmlets, respectively, in 1987, despite no lime having been applied to the farmlets since small amounts were applied to the HFHF farmlet in $1975(1250 \mathrm{~kg} / \mathrm{ha})$ and again in $1979(2500 \mathrm{~kg} / \mathrm{ha})$.

Average sulphate-S levels in the topsoil $(0-75 \mathrm{~mm})$ for the three slopes and aspects in the LFNF, LFLF and HFHF farmlets were 6,9 and $11 \mu \mathrm{g} / \mathrm{g}$, respectively. These reflected the fact that the LFLF and HFHF farmlets received annual S inputs in the superphosphate application.

Average quick test $\mathrm{Ca}$ levels in the topsoil (0-75 $\mathrm{mm}$ ) for the three slopes and three aspects in the LFNF, LFLF and HFHF farmlets were 2.7, 3.6, and $4.7 \mu \mathrm{g} /$ $\mathrm{ml}$, respectively, reflecting the fact that considerable amounts of $\mathrm{Ca}$ are applied in single superphosphate. The applications of 125 and $375 \mathrm{~kg}$ superphosphate/ha/year adds 25 and $75 \mathrm{~kg} \mathrm{Ca} /$ ha, respectively. Re-distribution of this divalent cation, along with exchangeable potassium $(\mathrm{K})$ is also evident, as is some depletion of $\mathrm{K}$ on steep slopes in the HFHF farmlet. Generally, there was little difference in quick test $\mathrm{K}$ levels across the farmlets. The exception was high $\mathrm{K}$ levels on the low slope areas in the HFHF farmlet. Exchangeable Mg levels declined on all slope classes in the HFHF farmlet, with the average for the farmlet at $16 \mu \mathrm{g} / \mathrm{ml}$, compared with 22 and 21 $\mu \mathrm{g} / \mathrm{ml}$ for the LFLF and LFNF farmlets, respectively. The soil Mg levels in the HFHF farmlet were below the optimum for livestock (20-25), but above the levels where a pasture response $(>10 \mu \mathrm{g} /$ $\mathrm{ml})$ would be expected. The loss of $\mathrm{Mg}$ is the result of a combination of factors, including nitrate and $\mathrm{SO}_{4}-\mathrm{S}$ leaching losses. Sakadevan et al. (1993) found the losses of sulphate-S to be 10 times higher than nitrate in drainage water below $250 \mathrm{~mm}$ soil depth. The high losses of S from the LFLF and HFHF farmlet explains why little $\mathrm{S}$ has accumulated in these soils over the last 40 years.

\section{Changes in soil phosphorus fertility}

The Olsen P levels in soil on the farmlet that has had no fertiliser since 1980 has dropped to $4 \mu \mathrm{g} / \mathrm{ml}$ (Figure 2), ranging now from 2 to $7 \mu \mathrm{g} / \mathrm{ml}$ across the 18 sites in the farmlet. The farmlet that has received $125 \mathrm{~kg} / \mathrm{ha} /$ year of superphosphate since 1980 (LFLF) averages $13 \mu \mathrm{g}$ / $\mathrm{ml}($ range 3-26 $\mu \mathrm{g} / \mathrm{ml}$ ) and the farmlet that has received $375 \mathrm{~kg} / \mathrm{ha} /$ year of superphosphate since 1980 (HFHF) averages $49 \mu \mathrm{g} / \mathrm{ml}$ (range 10-106 $\mu \mathrm{g} / \mathrm{ml}$ ).

In the LFLF farmlet the annual application of 125 $\mathrm{kg}$ superphosphate/ha/year has resulted in little change in Olsen $\mathrm{P}$ values, indicating the $\mathrm{P}$ fertiliser input is just balancing the P losses to soil, in product and by animal transfer within the paddock. This is matched by the fact there has been no change in the nominal long term average sheep stocking rate on the farmlet since 1980 (Mackay \& Lambert 2011). Until annual inputs are increased above maintenance no improvements in production are going to occur.

On the LFLF farmlet the average Olsen P values for the low, medium and high slope classes, were 25, 9 and $7 \mu \mathrm{g} / \mathrm{ml}$, respectively (Figure 3). In a commercial operation where the goal is to optimise the use of the land resource, the annual P fertiliser input to the LFLF farmlet would be increased to lift the Olsen P closer to $>20 \mathrm{ug} / \mathrm{ml}$ on the medium slope based on the sampling protocol and target Olsen P level for 97\% maximum pasture production in the recommendations of Morton \& Roberts (2009). Lambert et al. (2014) using pasture and soil data collected from the long term fertiliser and grazing study at Ballantrae from 1975 to 1998, found that the Olsen P level for $97 \%$ maximum pasture production was closer to $14-15 \mu \mathrm{g} / \mathrm{ml}$. The apparent difference in the critical Olsen P level between the two studies might reflect the fact that the calibration curve reported by Lambert et al. (2014) was from a single site, while the calibration curve reported by Morton \& Roberts (2009) comes from a large number of sites.

On the HFHF farmlet with Olsen P values averaged 88,34 and $27 \mu \mathrm{g} / \mathrm{ml}$ on the low, medium and high slope

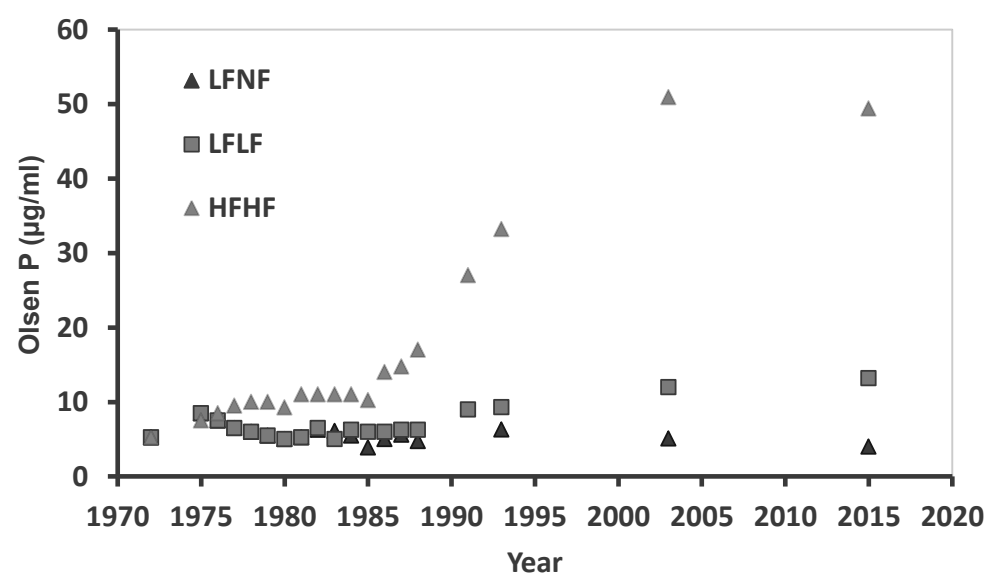

Figure 2 Changes in soil Olsen $\mathrm{P}$ levels $(\mu \mathrm{g} / \mathrm{ml})$ in the $0-75 \mathrm{~mm}$ soil depth in the farmlets that has had no fertiliser since 1980 (LFNF), received 125 $\mathrm{kg} / \mathrm{ha} / \mathrm{year}$ of superphosphate since 1980 (LFLF) or $375 \mathrm{~kg} / \mathrm{ha} / \mathrm{year}$ of superphosphate since 1980 (HFHF). 
classes, respectively (Figure 3), the recommendation if running a commercial operation, would be to reduce the superphosphate inputs by $100-125 \mathrm{~kg} / \mathrm{ha} /$ year, to bring the Olsen $\mathrm{P}$ values below 30 and closer to 20 . This would also reduce the risk of $\mathrm{P}$ losses in surface run-off (Parfitt et al. 2009). In the LFNF farmlet the average Olsen $\mathrm{P}$ levels were $<5 \mu \mathrm{g} / \mathrm{ml}$ on all slope classes (Figure 3), indicating a soil sample from any slope would be informative of the likely behaviour of the system to added $\mathrm{P}$ fertiliser.

The Olsen P levels in the soil in the HFHF farmlet have not increased since the last sampling in 2003 (Figure 2). Based on the Morton \& Roberts (2009) claim estimate of the amount of $\mathrm{P}$ above maintenance required (4-7 kg P/ha) to raise the Olsen $\mathrm{P}$ test by 1 unit for these soils should have translated into an increase of 10-20 units on the HFHF farmlet over the last decade. Lambert et al. (2000) observed that before 1990 the increase in Olsen P levels were lower and slower than predicted from the model used by Morton \& Roberts (2009). Lambert et al. (2000) assumed the discrepancy was because the grazing trial soils had a very limited previous fertiliser application history. Interestingly, while the changes in Olsen P levels on the HFHF farmlet from 1990 to 2003 aligned more closely with the changes predicted by the Morton \& Roberts (2009) model, the lack of changes in soil test values over the last 10 years (2003-2014) is more difficult to explain given that as the initial Olsen $\mathrm{P}$ level increases, less soluble $\mathrm{P}$ is required to increase the Olsen $\mathrm{P}$ by 1 unit (Edmeades et al. 2006).

\section{Changes in soil phosphorus fertility with depth}

Olsen P levels in the $75-150 \mathrm{~mm}$ soil depths in the low slope areas of the HFHF farmlet were higher than in the topsoil $(0-75 \mathrm{~mm})$ of either the LFLF or LFNF farmlets (Figure 3). This was a trend also noted at the sampling of the farmlets in 2003. Phosphorus, unlike nitrate- $\mathrm{N}$ is a specifically absorbed anion, and as a consequence has little mobility in soil accumulating in the topsoil. The exception would be in coarse textured soils, soils with low anion storage capacity, like podzols (Edwards et al. 1994) or where preferential flow occurs. The possible mechanisms for $\mathrm{P}$ movement down the profile in this study includes plant roots, inorganic and organic P movement (dissolved organic matter) in soil solution, P sorbed on clay minerals washed down cracks and channels as a consequence of preferential flow, and the incorporation and mixing of fertiliser material, plant litter and topsoil by earthworms. The movement of $\mathrm{P}$ to depth might explain in part the slower than predicted increase in Olsen P values in the top $75 \mathrm{~mm}$ of soil in the HFHF farmlet from the 1.4 times maintenance P applications over the preceding decade. The size of the increases in the Olsen P levels at the 75-150 mm depths challenges the notion that $\mathrm{P}$ is largely immobile and only

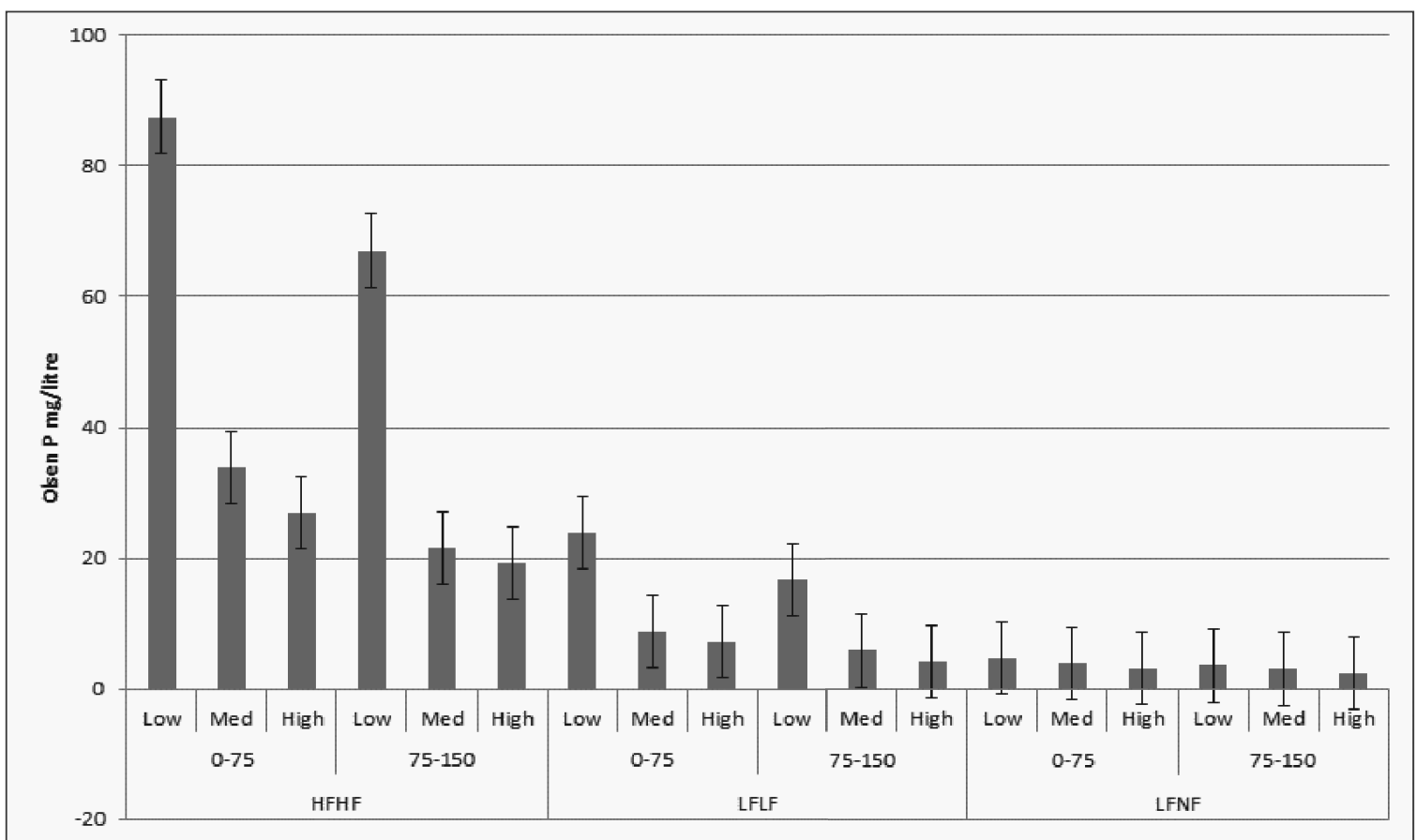

Figure 3 Changes in Olsen P levels $(\mu \mathrm{g} / \mathrm{ml})$ at 0-75 and $75-15 \mathrm{~mm}$ soil depths on low, medium and high slope areas on the farmlet that has had no fertiliser since 1980 (LFNF), received $125 \mathrm{~kg} / \mathrm{ha} / \mathrm{year}$ of superphosphate since 1980 (LFLF) or $375 \mathrm{~kg} /$ ha/year of superphosphate since 1980 (HFHF). Vertical lines are errors bars. 
small amounts of this nutrient move down through the profile. Into the future some thought might need to be given to increasing the depth of sampling to track and capture the changes in $\mathrm{P}$ levels in high $\mathrm{P}$ fertility systems.

\section{Conclusions}

Field sites with well documented, long-term diverse management histories, like the long term fertiliser and sheep grazing study at Ballantrae provide invaluable insights into the behaviour of our pastoral ecosystems beyond current knowledge, boundaries and calibrations. The longer these studies are run the more valuable they become.

\section{ACKNOWLEDGEMENTS}

All the science, technical and farm staff and service staff who have been involved at the AgResearch Hill Country Research Station, Ballantrae since its establishment. We are grateful for funding received from the Sustainable Land Use Research Initiative via a Plant and Food Research subcontract and the Fertiliser Research Association of New Zealand Incorporated.

\section{REFERENCES}

Clark, D.A.; Ledgard, S.F.; Lambert, M.G.; O’Connor, M.B.; Gillingham, A.G. 1990. Long term effects of withholding phosphate application on North Island hill country Economics. Proceedings of the New Zealand Grassland Association 51: 29-34.

Edmeades, D.C.; Metherell, A.K.; Waller, J.E.; Roberts, A.H.C.; Roberts, J.D. 2006. Defining the relationships between pasture production and soil $\mathrm{P}$ and the development of a dynamic P model for New Zealand pastures: a review of recent developments. New Zealand Journal of Agricultural Research 49: 207-222.

Edwards, J.; Gregg, P.E.H.; Mackay, A.D.; Richardson, M.A. 1994. Movement of phosphate in a Wharekohe podzol. Proceedings of technical workshop on 'Efficient use of fertilisers in a changing environment'. Occasional Report No. 7, pp. 318-325. Massey University, Palmerston North.

Lambert. M.G.; Clark, D.A.; Mackay, A.D. 1990. Long term effects of withholding phosphate application on North Island hill country: Ballantrae. Proceedings of the New Zealand Grassland Association 51: 25-28.

Lambert, M.G.; Clark, D.A.; Mackay, A.D.; Costall, D.A. 2000. Effects of fertiliser application on nutrient status and organic matter content of hill soils. New Zealand Journal of Agricultural Research 43: 127138.

Lambert, M.G.; Mackay, A.D.; Ganesh S.; Upsdell M.P. 2014. Response of grazed New Zealand hill pastures to rates of superphosphate application. New Zealand Journal of Agricultural Research 57: 149-164.

Mackay, A.D.; Lambert, M.G. 2011. Long-term changes in soil fertility and pasture production under no, low and high phosphorus fertiliser inputs Proceedings of the New Zealand Grasslands Association 73: 37-42.

Morton, J.; Roberts, A. 2009. Fertiliser use on New Zealand sheep and beef farms, p33. Fertiliser Association of New Zealand. http://www.fertiliser. org.nz/Site/resource_center/Booklets.aspx.

Parfitt, R.L.; Mackay, A.D.; Ross, D.J.; Budding P.J. 2009. Effects of soil fertility on leaching losses of N, P and C in hill country. New Zealand Journal of Agricultural Research 50: 69-80.

Saggar, S.; Mackay, A.D.; Hedley, M.J.; Lambert, M.G.; Clark, D.A. 1990. A nutrient transfer model to explain the fate of phosphorus and sulphur in a grazed hill country pasture. Agriculture, Ecosystems and Environment 30: 295-315.

Sakadevan, K.; Hedley, M.J.; Mackay, A.D. 1993. Mineralisation and fate of soil sulphur and nitrogen in hill pastures. New Zealand Journal of Agricultural Research 36: 271-281.

Smith, L.C.; Moss, R.A.; Morton, J.D.; Metherell, A.K.; Fraser, T.J. 2012. Pasture production from a longterm fertiliser trial under irrigation. New Zealand Journal Agricultural Research 55: 105-117. 
